\title{
Multidimensional Scaling Analysis of the Proximity of Photosynthesis Concepts In Korean Students
}

\author{
Youngshin Kim · Jae-hoon Jeong' · Soo-min Lim* \\ Kyungpook National University $\cdot{ }^{1}$ Dalsung Primary School
}

\begin{abstract}
Multidimensional scaling can be used to identify relationships among concepts, revealing the structure of the cognitive framework by measuring distances within perceptual maps. The current study sought to examine the relationships among concepts related to photosynthesis in $2,8443^{\text {rd }}-11^{\text {th }}$ grade science students. The questionnaire included items on 'location,' 'products,' 'reactants,' and 'environmental factors', presenting images related to each theme. Students provided responses corresponding to particular topics, and reported the extent to which the concept was related to the topic on a scale from 1 to 30. The survey results were as follows: first, students were not able to clearly distinguish between or understand the four main topics. Second, students organized their cognitive structures by closely associating related concepts after learning. Third, the presented concepts revealed a mixture of scientific and non-scientific concepts, suggesting that students needed to clearly distinguish the preconceptions through which they organized concepts, so that they are suitable for cognitive structures based on learning. Furthermore, nonscientific concepts within perceptions were consistently maintained throughout learning, affecting the proximity of scientific concepts.
\end{abstract}

Key words: multidimensional scaling (MDS), proximity, photosynthesis, location of photosynthesis, products of photosynthesis, reactants of photosynthesis, environmental factors

\section{Introduction}

According to constructivist theory, learners create their own knowledge by reconstructing new knowledge through connection with their existing knowledge, rather than directly accepting the knowledge and terms learned (Strike \& Posner, 1985; Taber, 2001). That is, learners tend to understand newly created knowledge within their own framework of meaning, rather than passively accepting knowledge delivered by teachers (Hewson \& Hewson, 1984). Moreover, since most learners understand new knowledge by constructing concepts rather than understanding individual terms themselves, it is necessary to understand the composition of the concepts perceived by learners (Riemeier \& Gropengieer, 2008). This composition can be examined by structural analysis of learners' cognitive frameworks.
The structure of a cognitive framework indicates how concepts are organized, and how closely related they are within a conceptual domain (Snow, 1989). Identifying the structure of a cognitive framework is important for instructors engaged in developing learning materials in accord with the way in which knowledge is perceived by learners (Ifenthaler et al., 2011).

Multi-dimensional scaling (MDS) is one of several methods for identifying the structure of cognitive frameworks. MDS is a multivariate analysis technique that identifies structural elements inherent in a data set, expressing the implicit representation of the data. MDS can identify criteria that can be used to evaluate similarity or dissimilarity between objects, and, for each criterion, each object can be visually represented in multi-dimensional space. Accordingly, the objective of the analysis is to

\footnotetext{
*Corresponding author: Soo-min Lim (bbolsar@naver.com)

${ }^{* *}$ Received on 9 March 2013, Accepted on 14 April 2013

***This research was supported by the Basic Science Research Program through the National Research Foundation of Korea (NRF) funded by the Ministry of Education, Science and Technology (No. 2010-0004133).
} 
determine the inherent meaning of dimensions by describing the similarity or dissimilarity of each object through the distance between objects in multi-dimension space (Borg \& Lingoes, 1987).

Within a person's cognitive framework, concepts are systematically organized in terms of similarity or relevance of meanings among related knowledge and terms (Caramazza \& Shelton, 1998; Masson, 1995; Sternberg, 2005; Tyler et al., 2000). The relationship between concepts can thus be represented in multidimensional space using MDS, which has a representative transfer function that shows the relationship among concepts in multidimensional space. Relational structures between concepts can then be analyzed based on the proximity function. The proximity of concepts included relationship between one concept and the other concept as well as relationships among concepts in complicated concept web.

Difficulties in understanding biological concepts have been reported for several important concepts that are commonly taught in the school education system (Riemeier \& Gropengieer, 2008; Yenilmez \& Tekkaya, 2006). Photosynthesis has been emphasized as one of the most important areas of biology education, and has been identified as an area with a number of prevalent misconceptions among learners (Canal, 1999; Griffard \& Wandersee, 2001; Krall et al., 2009). The concept of photosynthesis is a field wherein misconceptions can easily manifest from invisible phenomena (Wood-Robinson, 1991). However, few studies have focused on the relationships between learners' concepts about photosynthesis (Lim et al., 2012a, b). This study used MDS to analyze the difference of the relationships (proximities) between concepts about photosynthesis in $3^{\text {rd }}$ to $11^{\text {th }}$ grade students learning science in Korea.

\section{Theoretical Framework}

Concepts of Photosynthesis Taught in the 2007

\section{Revision Science Curriculum}

The 5th grade curriculum in Korea involves education about plant organs, while the $7^{\text {th }}$ grade curriculum focuses on the synthesis of nutrients related to photosynthesis within the nutrition of plants' unit. And life science subjects in high school focuses on photosynthesis mechanism (light and dark reaction) and location of photosynthesis within the 'cells and metabolism' unit. (Table 1)

The photosynthesis content in the nutrition of plants unit covers the process by which water and inactive nutrients are absorbed by the roots, transferred through the vascular bundle, and photosynthesized in the leaves. Furthermore, the principle and function of transpiration is taught in relation to photosynthesis (Ministry of Education, Science and Technology, 2008).

\section{The proximity of concepts using MDS}

The proximity of concepts was examined using MDS, a data-abbreviating multivariate analysis method that connotatively expresses data by identifying structure in datasets, similarly to cluster analysis. MDS has become a general data analysis method used in a variety of fields, including marketing, sociology, political science and biology. In marketing, MDS has been used in ecological theory applied to product markets by quantifying concepts like niches between brands (Milne \& Mason, 1989). In MDS, each individual data point is expressed visually in a multidimensional space by finding immanent meaning the dimensions that can be used to evaluate the similarities or differences between individuals. This method reveals distance between individuals that can explain the similarities or dissimilarities between individuals. In a perceptual map, the relationships between individuals are indicated by proximity. Higher proximity indicates a shorter distance between individuals and a stronger similarity relationship. Additionally, lower proximity indicates a longer distance 


\section{Table 1}

Main Contents of Units Related to Photosynthesis as Presented in the 2007 Revision Science Curriculum

\begin{tabular}{|c|c|c|c|}
\hline Subject & Unit & Sub-unit & Main Content \\
\hline \multirow{2}{*}{ Science } & \multirow{2}{*}{$\begin{array}{l}\text { Structure } \\
\text { and } \\
\text { Function of } \\
\text { Plants }\end{array}$} & Activities in the leaf & $\begin{array}{l}\text { Experimental observation of the formation of starch as the } \\
\text { product of transpiration and photosynthesis; experiments to } \\
\text { examine the products of photosynthesis }\end{array}$ \\
\hline & & $\begin{array}{l}\text { Relationships of the } \\
\text { root, stem, leaf, and } \\
\text { fruit }\end{array}$ & $\begin{array}{l}\text { The process of storing nutrients in the fruit after } \\
\text { transferring the water absorbed in the root to the stem, and } \\
\text { photosynthesis in the leaf }\end{array}$ \\
\hline \multirow{5}{*}{ Science } & \multirow{5}{*}{$\begin{array}{l}\text { Nutrition of } \\
\quad \text { Plants }\end{array}$} & Root & $\begin{array}{l}\text { How water and inactive nutrients are absorbed in the root } \\
\text { and used in photosynthesis }\end{array}$ \\
\hline & & Stem & $\begin{array}{l}\text { Structure and functions of the sieve tube and vessels that } \\
\text { compose the vascular bundle }\end{array}$ \\
\hline & & Leaf & Relationship of transpiration and photosynthesis \\
\hline & & Transpiration & Principle and function of transpiration \\
\hline & & Photosynthesis & $\begin{array}{l}\text { Substances formed and reactants of photosynthesis; } \\
\text { conversion and transference of nutrients formed as a result } \\
\text { of photosynthesis; examination of the factors that affect } \\
\text { photosynthesis }\end{array}$ \\
\hline $\begin{array}{l}\text { Life } \\
\text { Science } \\
\quad \text { II }\end{array}$ & $\begin{array}{l}\text { cells and } \\
\text { metabolism }\end{array}$ & Photosynthesis & $\begin{array}{l}\text { structure and functions of chloroplast, light reaction and } \\
\text { dark reaction of photosynthesis, examination of the factors } \\
\text { that affect photosynthesis }\end{array}$ \\
\hline
\end{tabular}

between individuals and a weaker similarity relationship (Borg \& Lingoes, 1987). That is, the proximity between concepts appearing in a perceptual map indicates that the awareness of students about the similarity between concepts.

The current study examined the proximity of concepts by analyzing the similarities between concepts using MDS, examining the relevance score and the frequencies of the concepts (Milne \& Mason, 1989).

\section{Research Methods}

\section{Subjects and data collection}

A total of 2,844 participants volunteered to take part in this questionnaire study, including 283 students from the $3^{\text {rd }}$ grade, 319 students from the $4^{\text {th }}$ grade, 310 students from the $5^{\text {th }}$ grade, 316 students from the $6^{\text {th }}$ grade, 315 students from the $7^{\text {th }}$ grade, 294 students from the $8^{\text {th }}$ grade, 323 students from the $9^{\text {th }}$ grade, 337 students from the $10^{\text {th }}$ grade, and 347 students from the $11^{\text {th }}$ grade. Even though $3^{\text {rd }}$ and $4^{\text {th }}$ grade students did not learn photosynthesis, the subjects consist of $3^{\text {rd }}$ and $4^{\text {th }}$ students. Students have misconception before the lesson. And these misconceptions are effect on future learning. The reason why subjects consist of $3^{\text {rd }}$ and $4^{\text {th }}$ students is in order to analyze the effect on misconceptions that students have before the lesson. For $3^{\text {rd }}$ and $4^{\text {th }}$ students that didn't know about concept of the photosynthesis, I asked teachers to explain about concept of the photosynthesis before questionnaire survey.

Data collection was carried out from May to June 2011, before the students discussed photosynthesis in class that year. The study was 
explained to both biology teachers and students before the research began. Science teachers were in charge of supervising the survey, and sufficient time was provided to obtain the responses on the questionnaire. The questionnaire took between 20 and 30 minutes to complete.

\section{Questionnaires}

For the science curriculum in Korea, the lesson on photosynthesis is designed for $5^{\text {th }}, 7^{\text {th }}$, and $10^{\text {th }}$ grade students, consisting of 'location of photosynthesis,' 'products of photosynthesis,' 'reactants of photosynthesis', and 'environmental factors' (Chung et al., 2005). Accordingly, we divided the concepts involved in photosynthesis into these four areas, and presented pictures of photosynthesis-related experiments related to each area, based on the analysis of topics relevant to photosynthesis as printed in a science textbook (see Appendix). Appendix presented is an example in which any of the study four areas. In the case of the remaining regions, questionnaires are made of the same format with different images for each area.

Students were required to respond to concepts they knew by referring to the experimental pictures presented in each area, then report the degree of relevance for the concepts associated with the area on a scale from 1 to 30 points. The questionnaires were developed through modifying and supplement, based on consultation with biology experts, science educators, cognitive psychology experts, and biology teachers. The validity of the questionnaires was $83.3 \%$, using a 5-point Likert system(1=very low, $2=$ low, 3 = average, 4 = high, 5=very high), measured ) by five educational biology researchers.

\section{Data analysis}

The proximity between concepts was analyzed using a perceptual map produced by MDS.
Concepts with a frequency of $5 \%$ or more were targeted, based on the vegetation regions method (in the field of ecology) that selects species with a frequency of more than 5\% to extract representative subjects among the distributed species (Lee et al., 1998). We used SPSS $17.0 \mathrm{~K}$ to analyze proximity data by including concepts with a frequency rate of more than $5 \%$, and by the mean of the relevance scores for concepts that were presented by students.

A perceptual map is a series of statistical techniques used to process numerical data on objective or subjective relationships to explain the similarity or dissimilarity between different objects, indicating the location of objects on a multi-dimensional space. MDS provides an overall representation of the relational structure of similarity. The relationship between objects is indicated by proximity; and thus the higher the similarity relationship is (Borg \& Lingoes, 1987). That is, the proximity between concepts appearing in a perceptual map shows that the awareness of students of the similarity between concepts is rather high.

\section{Results and Discussion}

\section{Location of photosynthesis}

Figure 1 shows prevalent concepts (occurring with a frequency of more than $5 \%$ based on ecological method) in close proximity to the concept of the location in which photosynthesis occurs among $3^{\text {rd }}$ to $11^{\text {th }}$ graders. The number of close-proximity concepts with a frequency of more than 5\% ranged from four to seven concepts; $9^{\text {th }}$ graders reported the largest number of close-proximity concepts with a frequency of at least $5 \%$, with seven concepts, while the $3^{\text {rd }}$, $4^{\text {th }}$, and $8^{\text {th }}$ graders recorded the smallest number, with four concepts.

For concepts not related to the location of photosynthesis, 'water' and 'roots' showed a high frequency. Among these, 'water' was 
prevalent for $3^{\text {rd }}$ grade to $9^{\text {th }}$ grade students, while 'roots' was prevalent among the $3^{\text {rd }}, 4^{\text {th }}$, and $5^{\text {th }}$ grade students, disappeared among the $6^{\text {th }}, 7^{\text {th }}$, and $8^{\text {th }}$ grade students, and reappeared among the $9^{\text {th }}$ grade students. This result corresponds to the common photosynthesisrelated misconception that plants obtain nutrients from soil or rainwater and absorb nutrients from the roots (Haslam \& Treagust, 1987). In response to the question regarding scientific concepts related to the location of photosynthesis, elementary school students answered, 'leaf,' while junior high school students answered, 'chloroplast.'

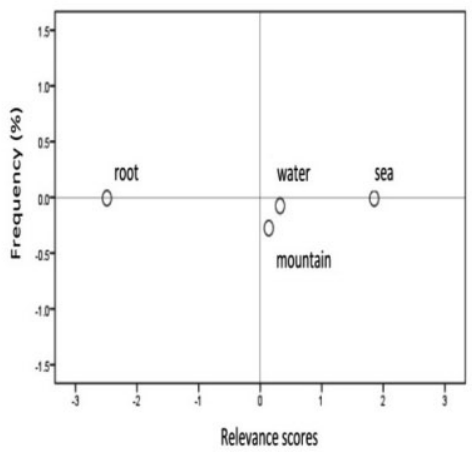

a. $3^{\text {rd }}$ grade

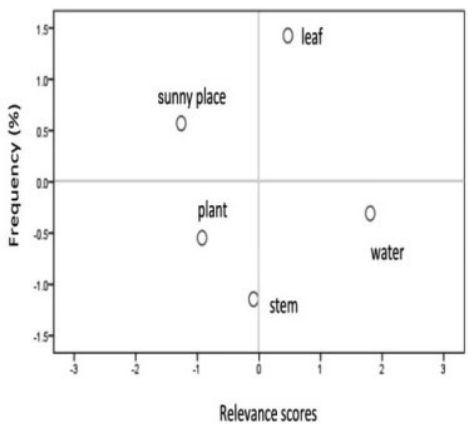

d. $6^{\text {th }}$ grade

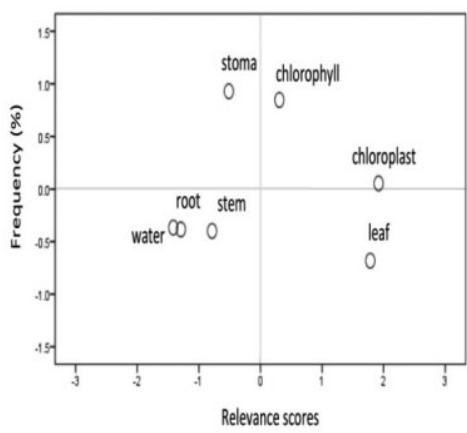

g. $9^{\text {th }}$ grade

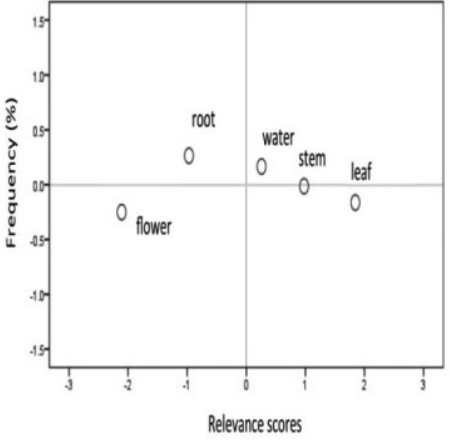

b. $4^{\text {th }}$ grade

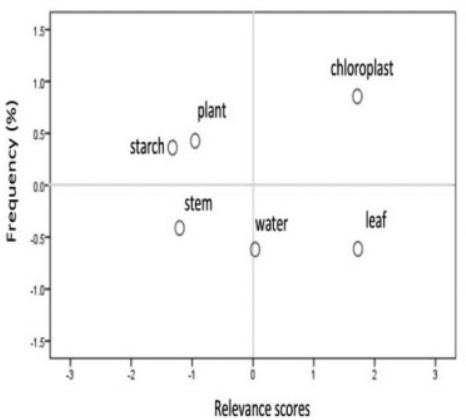

e. $7^{\text {th }}$ grade

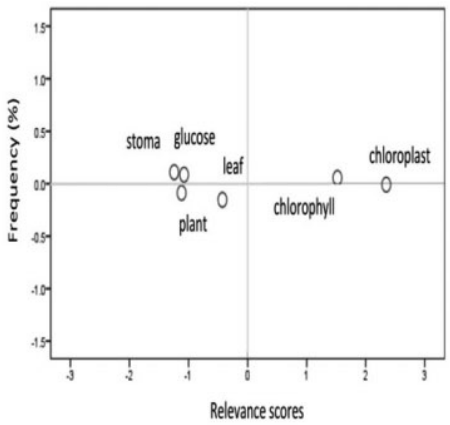

h. $10^{\text {th }}$ grade

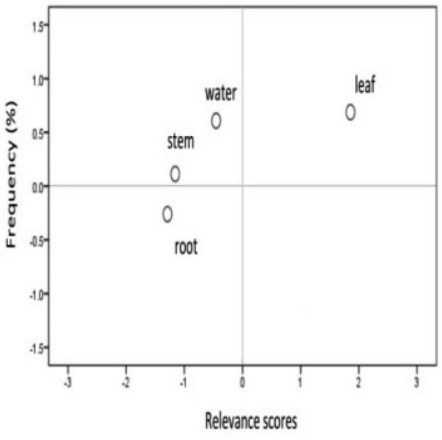

c. $5^{\text {th }}$ grade

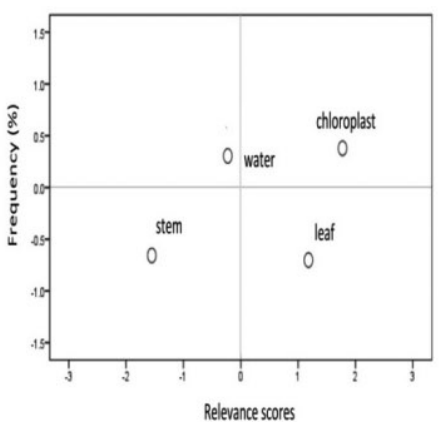

f. $8^{\text {th }}$ grade

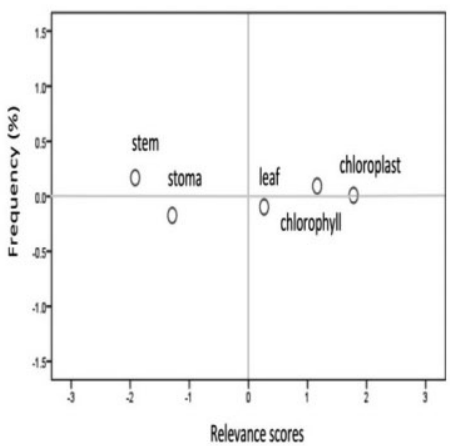

i. $11^{\text {th }}$ grade

Fig. 1 The proximity of concepts for the domain location of photosynthesis' 
In the Korean educational curriculum, $5^{\text {th }}$ graders are taught that photosynthesis occurs in 'leaves' while $7^{\text {th }}$ graders are taught that it takes place in 'chloroplasts'. We found that these two concepts were present at the same time from the $7^{\text {th }}$ grade onwards, and the proximity of the two concepts increased with age. In particular, these concepts were closer for $10^{\text {th }}$ and $11^{\text {th }}$ graders compared with other grade levels.

A previous study reported that students commonly have prior knowledge about the location of photosynthesis from everyday life before learning about it at school like flower, mountain (Confrey, 1987). Even after learning about photosynthesis, 'Structure and function of plants, as presented in the $5^{\text {th }}$ grade curriculum, students did not report close proximity of concepts at a frequency of more than $5 \%$. This may be because of misconceptions regarding the location of photosynthesis due to lack of a comprehensive understanding of the structure and function of plants before learning about them in school

Moreover, concepts related to 'water' meaning misconception in this area appeared at almost all grade levels, indicating that misconceptions were maintained even after implementation of concept instruction, in accord with previous reports (Haslam \& Treagust, 1987). Meanwhile, the concepts of chloroplast and chlorophyll were prevalent among students in the $9^{\text {th }}, 10^{\text {th }}$, and $11^{\text {th }}$ grades, indicating common confusion between 'chloroplast' and 'chlorophyll,' a photosynthetic pigment in accord with previous reports (Chung, 1993). These two terms have previously been reported to cause confusion because of their similarity (Cho, 1994).

\section{Products of photosynthesis}

Figure 2 shows the concept proximity for products of photosynthesis. The number of concepts with a frequency of more than 5\% ranged from five to eight among students of different grade groups. Five concepts with more than $5 \%$ frequency were present among $6^{\text {th }}, 10^{\text {th }}$, and $11^{\text {th }}$ graders, while $7^{\text {th }}$ grade students reported eight common close-proximity concepts.

Regarding products of photosynthesis, unrelated concepts, such as energy, vitamins, leaves, protein, fruits, and carbon dioxide occurred together. 'Nutrient' was common among $7^{\text {th }}$ graders, but not $8^{\text {th }}$ graders. This appeared to reflect confusion among $7^{\text {th }}$ graders regarding starch-related substances generated by photosynthetic reactions of plants with nutrients required for organisms to live, including starches. In particular, since students are taught that animals feed on plants for nutrients in the Korean curriculum, they may be likely to have the misconception that starches and nutrients are the same, causing them to think of nutrients as products of photosynthesis. In addition, students reported reactants of photosynthesis, such as carbon dioxide and water, in the area of products of photosynthesis, possibly because they did not recognize the distinction between the products of photosynthesis and the reactants of photosynthesis. Similar findings were reported in a previous study of concept proximity according to the levels of scientific attitudes among 7th grade students (Lee et al., 2012; Lim et al., 2012).

Carbon dioxide was mentioned as a product of photosynthesis by almost all students in all grades. This result seems to come from the linkage learning of photosynthesis and respiration (Ministry of Education, Science and Technology, 2008), and from the enhanced awareness of students of the relationship between the products of photosynthesis and respiration. On the other hand, misconceptions regarding the relationship between photosynthesis and respiration were also found in previous reports (Kose, 2008).

Students in the $5^{\text {th }}$ grade suggested starch and oxygen as products of photosynthesis through starch detection experiments, while $7^{\text {th }}$ grade 


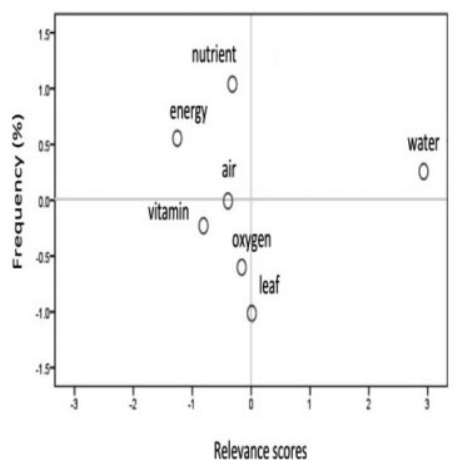

a. $3^{\text {rd }}$ grade

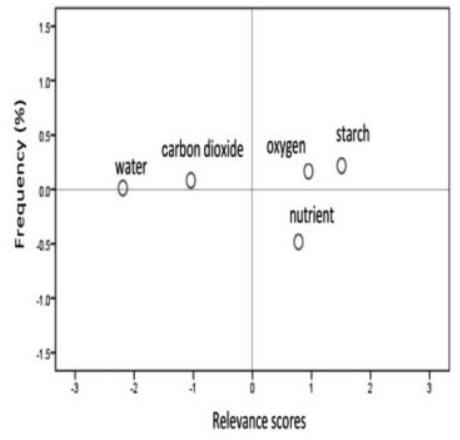

d. $6^{\text {th }}$ grade

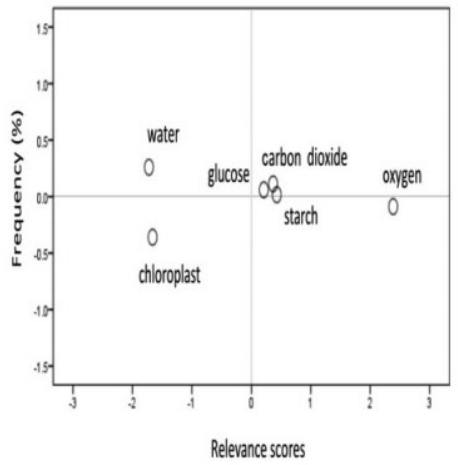

g. $9^{\text {th }}$ grade

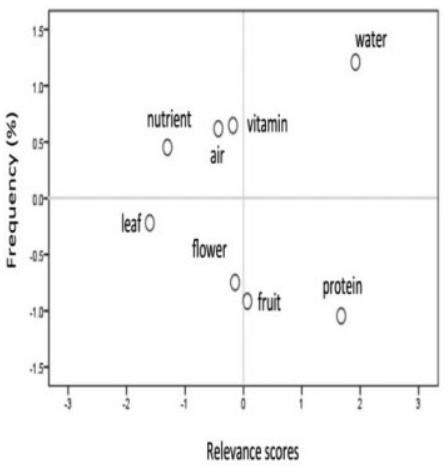

b. $4^{\text {th }}$ grade

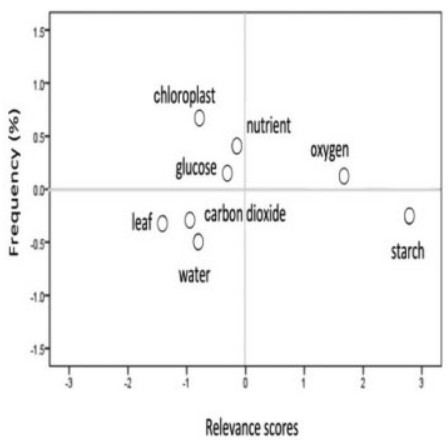

e. $7^{\text {th }}$ grade

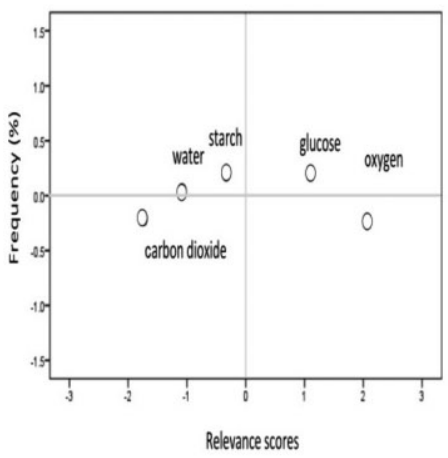

h. $10^{\text {th }}$ grade

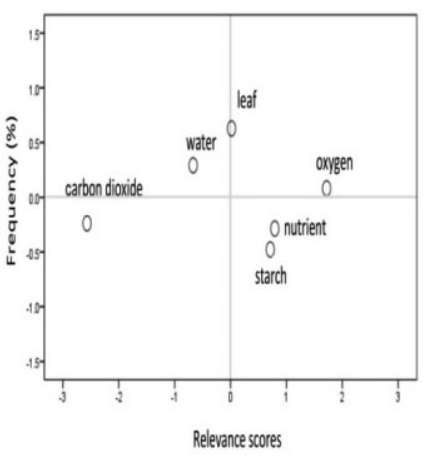

c. $5^{\text {th }}$ grade

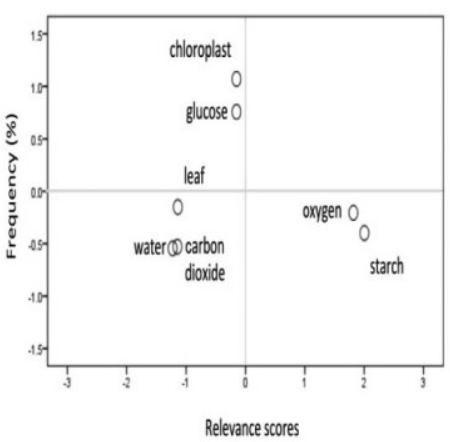

f. $8^{\text {th }}$ grade

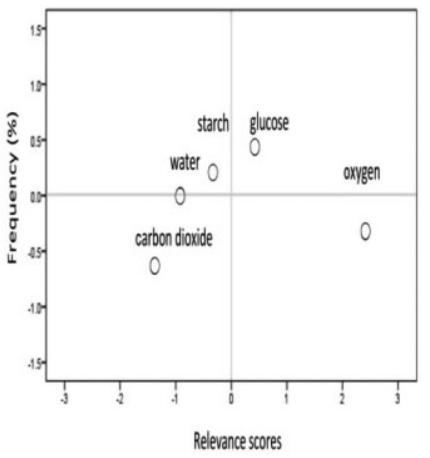

i. $11^{\text {th }}$ grade

Fig. 2 The proximity of concepts for the domain on 'products of photosynthesis'

students reported details of glucose production, being stored as starch. The terms 'starch' and 'oxygen,' which are related to the area of products of photosynthesis, turned out to be closer in proximity than any other concepts.

\section{Reactants of photosynthesis}

In the reactants of photosynthesis domain (see Figure 3), the number of concepts with more than $5 \%$ frequency ranged from four to six 
depending on the grade. Four concepts appeared in the $3^{\text {rd }}, 9^{\text {th }}, 10^{\text {th }}$, and $11^{\text {th }}$ grades, while the $4^{\text {th }}$ and $6^{\text {th }}$ grades reported six concepts. Although younger students suggested air as a material needed for photosynthesis, by the $5^{\text {th }}$ grade students referred to air and oxygen together, and by the $7^{\text {th }}$ grade they tended to suggest oxygen but not air as a reactant of photosynthesis. By linkage learning of photosynthesis and respiration, the concept of 'oxygen' in products of photosynthesis was linked incorrectly to the knowledge that oxygen is needed in the respiration of plants. This finding may also suggest that students are confused about the relationship between respiration and photosynthesis of plants (Kose, 2008).

Students in almost all grades reported water, carbon dioxide, and light as materials needed for photosynthesis. Among the four areas related to photosynthesis, reactants of photosynthesis elicited fewer non-scientific concepts than the other areas, and showed closer proximity among scientific concepts (water, carbon dioxide, and light) compared to non-scientific concepts. In particular, the elements of water, carbon dioxide, and light became closer as the grade level increased in terms of dimension 1 (relevance scores), indicating that concepts about the reactants of photosynthesis were clarified, and awareness of the relevance among scientific concepts is enhanced as a result of higher education.

\section{Environmental factors}

In terms of environmental factors, the number of related concepts reported with more than 5\% frequency ranged from three to seven depending on the grade. Fifth graders suggested three concepts, while $3^{\text {rd }}$ and $11^{\text {th }}$ grade students reported seven concepts. The concept of 'light' was reported by students in all grades. Third grade students reported a wide range of environmental factors around plants, but as the grade level increased, the concepts reported by students were largely limited to concepts directly related to photosynthesis.

In particular, students in the $10^{\text {th }}$ grade suggested environmental factors that affect photosynthesis in more detail. Until the 9th grade, students reported only two concepts of carbon dioxide and light, but by the $10^{\text {th }}$ grade, these concepts were reported in more detail. In particular, carbon dioxide was subdivided into carbon dioxide and the concentration of carbon dioxide, and light into light and the intensity of light. These results appear to be related to the high school curriculum, which teaches that the concentration of carbon dioxide and the intensity of light are environmental factors that affect photosynthesis. In addition, the fact that $10^{\text {th }}$ grade students had an understanding of these concepts before being exposed to the high school curriculum is presumed to indicate the results of prior learning. Meanwhile, students' reports of 'oxygen' as an environmental factor that affects photosynthesis indicates that concepts of photosynthesis and respiration of plants were linked through instruction, thereby contributing to an enhanced of awareness of students about the relevance of oxygen.

These findings have several implications for education. First, students did not appear to have a clear understanding of the distinction between the location of photosynthesis, products of photosynthesis, reactants of photosynthesis, and environmental factors that affect photosynthesis. This indicates the importance of helping students understand photosynthesis-related concepts via the separation of areas through teaching methods in which students themselves collect experimental materials related to photosynthesis and conduct inquiry-based learning activities (Ray \& Beardsley, 2008).

Second, students were found to organize cognitive structures by closely connecting concepts related to certain areas of photosynthesis through their classes. This indicates the importance of correlating scientific 


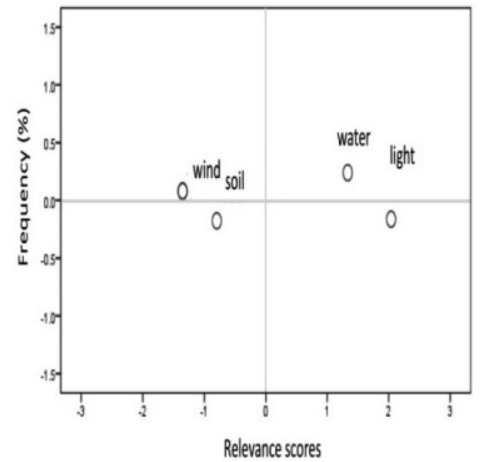

a. $3^{\text {rd }}$ grade

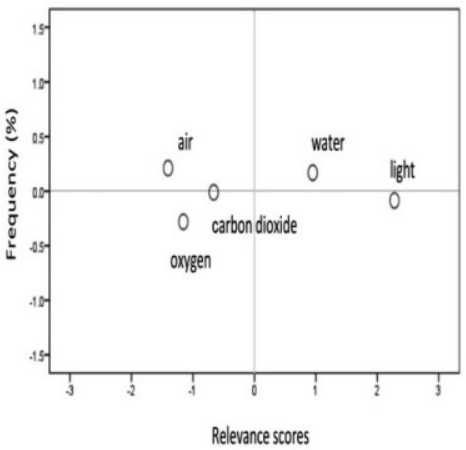

d. $6^{\text {th }}$ grade

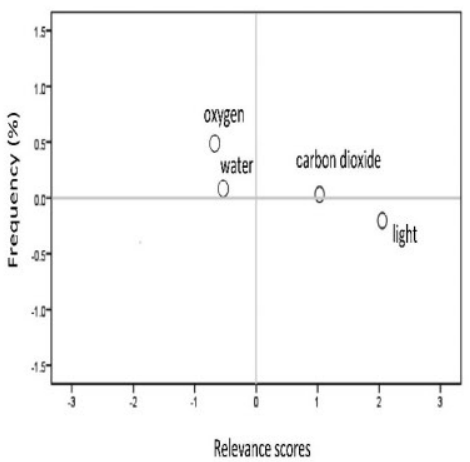

g. $9^{\text {th }}$ grade

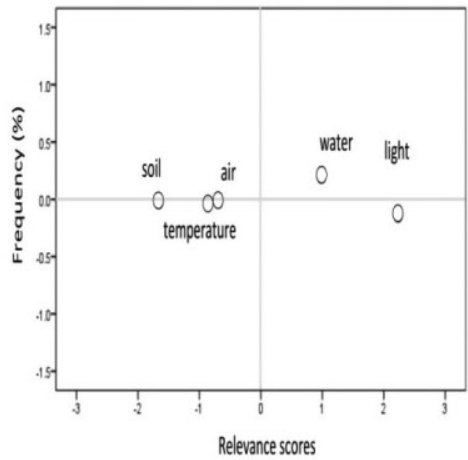

b. $4^{\text {th }}$ grade

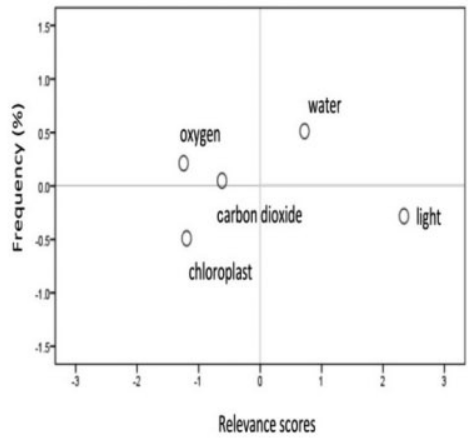

e. $7^{\text {th }}$ grade

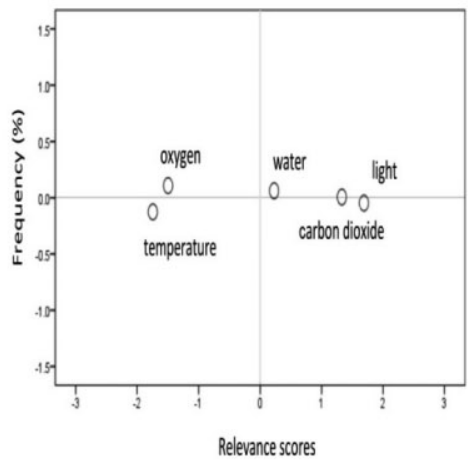

h. $10^{\text {th }}$ grade

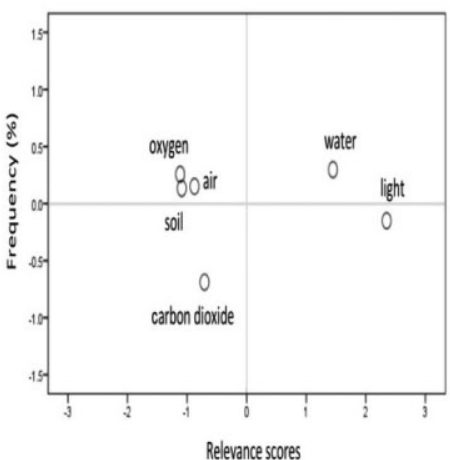

C. $5^{\text {th }}$ grade

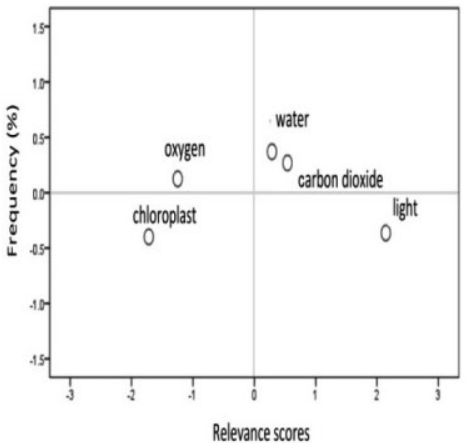

f. $8^{\text {th }}$ grade

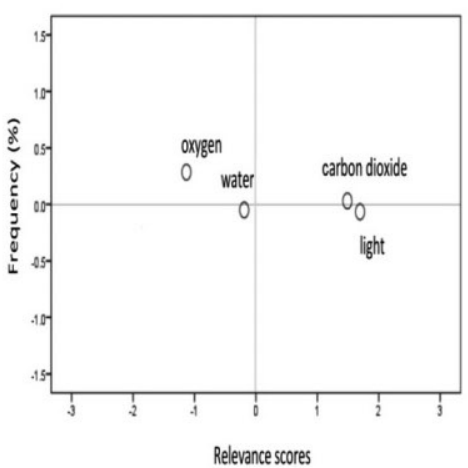

i. $11^{\text {th }}$ grade

Fig. 3 The proximity of concepts for the domain 'reactants of photosynthesis'

concepts with mutual connections by implementing lesson plans for more engaging and effective instruction about the concept of photosynthesis.

Third, scientific and non-scientific concepts related to photosynthesis were mixed together. This finding suggests that it may be necessary to correct and update students' prior conceptions through their classes. In addition, the current results still revealed that students often possess 


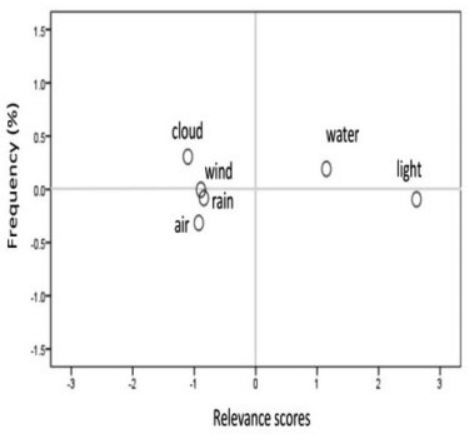

a. $3^{\text {rd }}$ grade

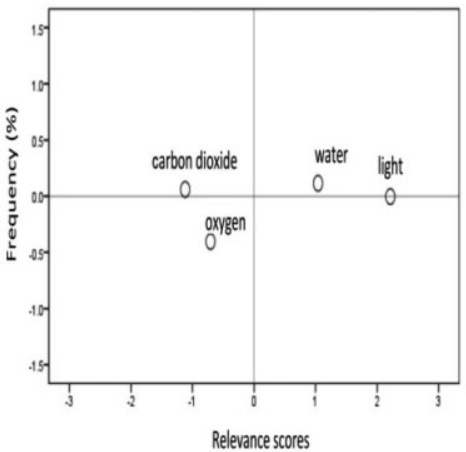

d. $6^{\text {th }}$ grade

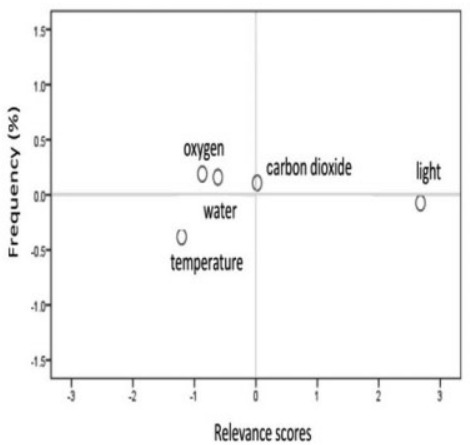

g. $9^{\text {th }}$ grade

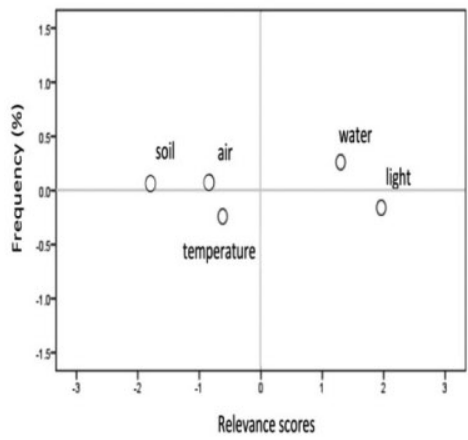

b. $4^{\text {th }}$ grade

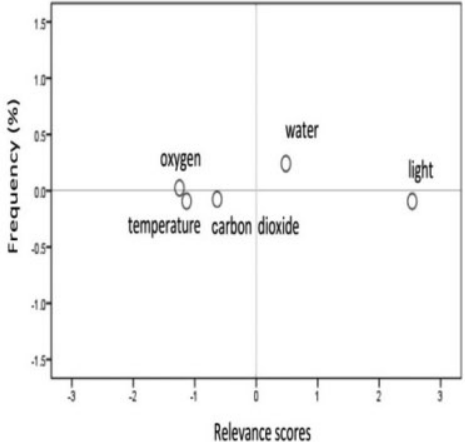

e. $7^{\text {th }}$ grade

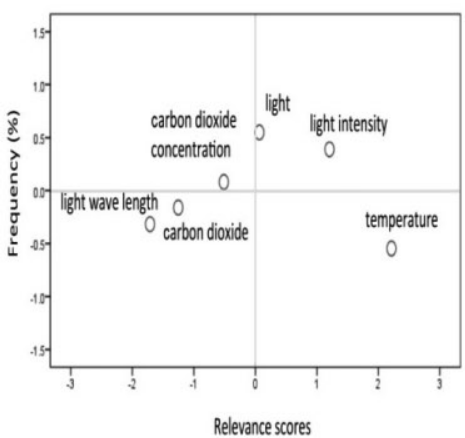

h. $10^{\text {th }}$ grade

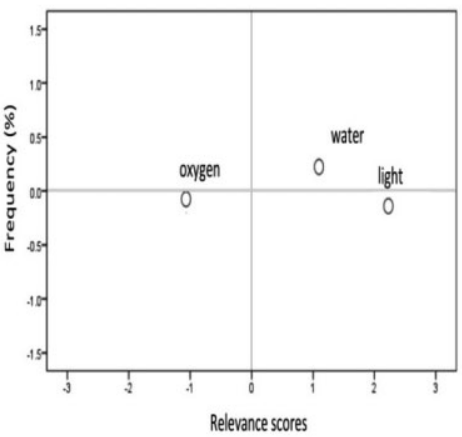

C. $5^{\text {th }}$ grade

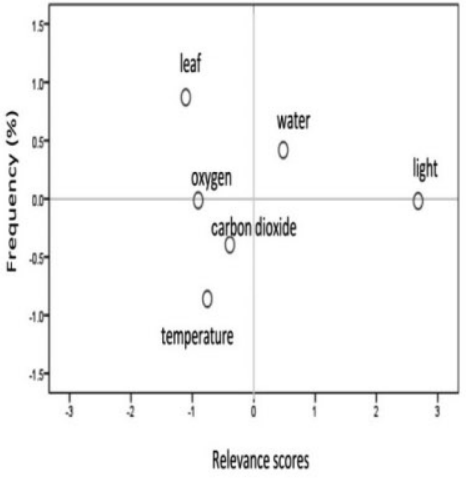

f. $8^{\text {th }}$ grade

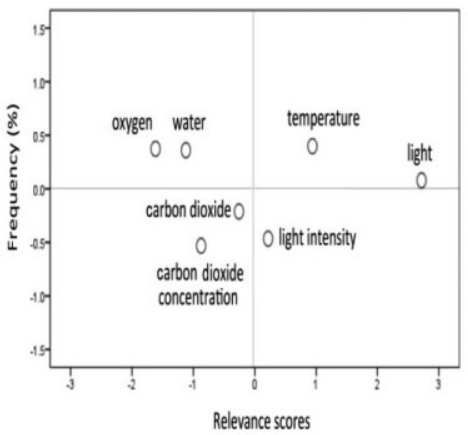

i. $11^{\text {th }}$ grade

Fig. 4 The proximity of concepts for the domain 'environmental factors'

many prior non-scientific concepts related to photosynthesis, even though the concentration of scientific concepts related to photosynthesis was found to increase, and the number of nonscientific concepts (prior conceptions) decreased with education in previous findings (Manuel, 2005). Thus, it is necessary to formulate examples and clear explanations to distinguish between scientific and non-scientific concepts while designing lesson plans, and to monitor 
progress so that students can establish scientific concepts about the different areas of photosynthesis.

\section{Conclusion}

Identifying the ways in which concepts are organized within cognitive areas among students is an important task for education research. The current study investigated the structure of concepts within cognitive areas by examining the difference of the proximity of concepts related to photosynthesis among $3^{\text {rd }}$ to $11^{\text {th }}$ grade students in Korea.

The results revealed that the proximity of students' concepts changed through acquisition of concrete concepts in class. In relation to environmental factors that affect photosynthesis, the concepts of air and wind were replaced by carbon dioxide and concentration of carbon dioxide in detail as education proceeded. In addition, the concept of light later became the concept of the intensity of light, leaf developed to chloroplast, and nutrients were subdivided into starch and glucose. As existing concepts were replaced by concrete concepts, the proximity between related scientific concepts increased, indicating that learners succeeded in composing and organizing the concepts that best suited their cognitive structures, grouping related terms through learning (Hewson, 1992; Taber, 2001).

Second, a number of non-scientific concepts appearing among elementary school students were also found in middle school students. In relation to the location of photosynthesis, the concept 'roots' appeared among elementary school students as well as middle school students. In materials generated through photosynthesis, carbon dioxide appeared among elementary and middle school students. Meanwhile, non-scientific concepts also appeared through learning. For instance, the concept of chlorophyll appeared among high school students in relation to the location of photosynthesis, likely because of the similarity of the two terms (chloroplast and chlorophyll). The fact that non-scientific concepts appear through learning indicates that scientific concepts are not structured into cognitive structures even through learning, and nonscientific concepts have an effect on the proximity of scientific concepts.

Third, students were found to closely recognize the concepts associated with each other in the four main areas of photosynthesis-related concepts. For example, the concepts of photosynthetic products and reactants of photosynthesis appeared in relation to questions about the location of photosynthesis. In addition, the reactants of photosynthesis were also reported in relation to the products of photosynthesis, which indicates that students are confused about the location of photosynthesis and the reactants of photosynthesis, as well as the relation between the products and reactants of photosynthesis. In other words, our results could be interpreted as indicating that students develop confusion about concepts related to products and reactants of photosynthesis as a result of learning, connecting photosynthesis with respiration. Accordingly, it is necessary to formulate guiding strategies that are more specific in education about photosynthesis and respiration through the linkage of biochemical reactions, in addition to the mere connection of gas exchange.

\section{References}

Borg, I., \& Lingoes, J. (1987). Multidimensional similarity structure analysis. New York: Springer.

Canal, P. (1999). Photosynthesis and inverse respiration in plants: An inevitable misconception?. International Journal of Science Education, 21(4), 363-371.

Caramazza, A., \& Shelton, J. (1998). Domainspecific knowledge systems in the brain: The animate-inanimate distinction. Journal of 
Cognitive Neuroscience, 10(1), 1-34.

Cho, H. (1994). Scientific concepts easy to misunderstanding. Seoul: Jeonpa-science Printing \& Publishing Company.

Chung, H., Park, H., Lim, Y., \& Lim, J. (2005). The analysis of the connection of the terms and the inquiry about the photosynthesis in the middle and high school science textbooks by the 7th curriculum. The Korean Journal of Biological Education, 33(2), 196-208.

Chung, W. (1993). A study on the biological misconceptions of Korean high school students. PhD diss., Seoul National University, Korea.

Confrey, J. (1987). "Misconceptions" across subject matters: Science, mathematics and programming. Proceedings of the Second International Seminar on Misconceptions and Educational Strategies in Science and Mathematics, 1, pp.81-106. Ithaca, New York: Cornell University.

Griffard, P., \& Wandersee, J. (2001). "The two-tier instrument on photosynthesis: What does it diagnose?". International Journal of Science Education, 23(10), 1039-1052.

Haslam, F., \& Treagust, D. (1987). Diagonising secondary students' misconceptions of photosynthesis and respiration in plants using two-tier multiple choice instruction. Journal of Biological Education, 21(3), 203-211.

Hewson, P. (1992). Conceptual change in science teaching and teacher education. Paper presented at a meeting on "Research and Curriculum Development in Science Teaching", Madrid: Spain, June 1992.

Hewson, P., \& Hewson, A. (1984). The role of conceptual conflict in conceptual conflict in conceptual change and the design if science instruction. Instructional Science, 13(1), 1-13.

Ifenthaler, D., Masduki, I., \& Seel, N. (2011). The mystery of cognitive structure and how we can detect it: tracking the development of cognitive structures over time. Instructional Science, 39, 41- 61.

Kose, S. (2008). Diagnosing student misconconceptions: Using grawings as a research method. World Applied Sciences Journal, 3(2), 283-293.

Krall, R., Lott, K., \& Wymer, C. (2009). Inservice elementary and middle school teachers' conceptions of photosynthesis and respiration. Journal of Science Teacher Education, 20, 41-55.

Lee, H., Byun, D., \& Kim, C. (1998). Analysis of interspecific association and ordination on the forest vegetation of Mt. Odae. Korean Journal of Ecology, 21(3), 291-300.

Lee, H. (2012). Analysis of concept's diversity and proximity of 7th grade students' photosynthesis concepts by the level of science attitude. MD thesis, Kyungpook National University, Korea.

Lim, S., Yoon, I., \& Kim, Y. (2012a). Analysis of level of understanding of $7^{\text {th }}$ and $8^{\text {th }}$ grade students on photosynthesis concepts by curriculum revision. The Korean Society of Biology Education, 40(2), 179-194.

Lim, S., Jeong, J., \& Kim, Y. (2012b). Analysis of concept's diversity and proximity for photosynthesis in grade 7 students. The Korean Association for Science Education, 32(6), 10501062.

Manuel, C. (2005). Ecology -Concept and Applications-. New York: McGraw-Hill.

Masson, M. (1995). A distributed memory model of semantic priming. Journal of Experimental Psychology: Learning, Memory, and Cognition, 21(1), 3-23.

Milne, G., \& Mason, C. (1989). An ecological niche theory approach to the measurement of brand competition. Marketing Letters, 1(3), 267281.

Ministry of Education, Science and Technology (2008). Middle school curriculum(II): Mathematics, science, technology. Seoul: Daehan Printing \& Publishing Company.

Ray, A., \& Beardsley, P. (2008). Overcoming student misconceptions about photosynthesis: a model and inquiry based approach using aquatic plants. Science Activities, 45(1), 13-22.

Riemeier, T., \& Gropengieer, H. (2008). On the roots of difficulties in learning about cell 
division: Process-based analysis of students' conceptual development in teaching experiments. International Journal of Science Education, 30(7), 923-939.

Snow, R. (1989). Toward assessment of cognitive and conative structures in learning. Educational Researcher, 18(9), 8-14.

Sternberg, R. (1999). Cognitive psychology (2nd ed.). New York: Harcourt Brace.

Strike, K., \& Posner, G. (1985). A conceptual change view of learning and understand. In $\mathrm{L}$. H. T. West, \& A. L. Pines(Eds), Cognitive Structure and Conceptual Change. Orlando, FL: Academic Press.

Taber, K. (2001). Shifting sands: A case study of conceptual development as competition between alternative conception. International Journal of Science Education, 23(7), 731-753.

Tyler, L., Moss, H., Durrant-Peatfield, M., \& Levy, J. (2000). Conceptual structure and the structure of concepts: A distributed account of category-specific deficits. Brain and Language, 75(2), 195-231.

Wood-Robinson, C. (1991). Young people's ideas about plants. Studies in Science Education, 19, 119-135.

Yenilmez, A., \& Tekkaya, C. (2006). Enhancing students' understanding of photosynthesis and respiration in plant through conceptual change approach. Journal of Science Education and Technology, 15(1), 81-87. 


\section{Appendix}

\section{Location of Photosynthesis}
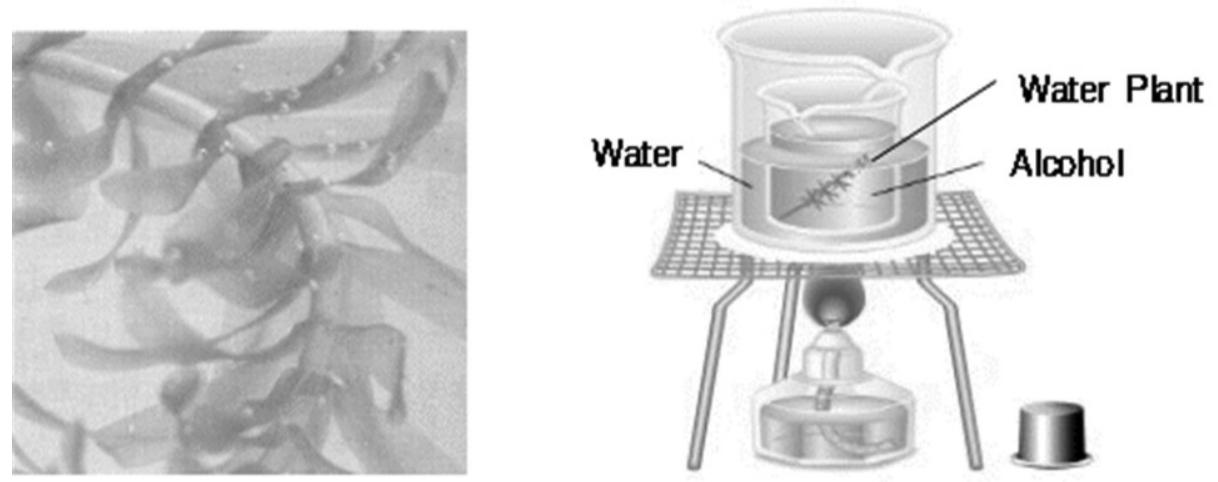

Water Plant

The experiment shows the location of photosynthesis using a water plant.

Please complete the questionnaire using the figure and your knowledge. When you fill in the table, please write down concepts related to the subject 'Location of Photosynthesis' and the degree of relevance of that concept to the subject "Location of Photosynthesis" in the form of a relevance score. This relevance score is indicated according to the degree of relevance with the domain, as judged by you, on a scale of 1 to 30 .

The relevance score is rated from 1 to 30. If you think that the degree of relevance among the concepts is the same, you can give the same score.

\begin{tabular}{|l|l||l|l||l|l|}
\hline Concept & $\begin{array}{c}\text { Relevance } \\
\text { Score }\end{array}$ & Concept & $\begin{array}{c}\text { Relevance } \\
\text { Score }\end{array}$ & Concept & $\begin{array}{c}\text { Relevance } \\
\text { Score }^{2)}\end{array}$ \\
\hline \hline & & & & & \\
\hline & & & & & \\
\hline & & & & & \\
\hline
\end{tabular}

